\title{
IMPACT OF THE PEER REVIEW PROGRAM ON HOSPITALS AND PHYSICIANS
}

Mohammad N. Akhier, M.D., M.P.H.

DOI: http://dx.doi.org/10.5915/18-1-11731

\begin{abstract}
Prospecive Payment Sy'stem DRGs are designed to limil the amouml of payment lo a hospital for any particular diagnosis, and the Peer Review Organizalions are to police hospiral activisies. In every state, there is a PRO having a contract with the Heolth Care Financing Administration 10 perforin the following functions:

(1) Review of reasonableness, necessity, and appropriateness of hospilal admissions.

(2) Validation of diagnosis for delermination of Medicare reimbursemen.

(3) Review of completeness and quality of care provided.

(4) Review of completeness and approprialeness of oullier cases.

Gelling a patient admitled to the hospilal isn't us easy as it used to be, and it is going to become increasingly difficult. For a physician, it all adds up to another level of imerference with which we haven't had to deal before.

The overall PRO progrum, including preadmission cerlificalion and the retrospecive review process. is discussed in this arlicle. The focus is on recommendations for physicians of "How la survive under the "rospective Payment System and the PRO program."
\end{abstract}

Introduction

Many studies have shown tremendous variation in medical care from one region to anolher and from one city to anolher. Residents of some cities are up to 20 times more likely to be hospitalized for ccrtain medical problems than residents of other cities in the same state. This variation in medical practicc suggests to the Healsh Care Financing Administration (HCFA) officials and Congress that there are unnecessary admissions to hospitals and probably, in some instances, unnecessary Ireatment being provided 10 palients. Unnecessary treatment is treatment which has no reasonable probability of improving the pa(ient's condition. HCFA believes that in areas of high utilization, a very substantial amount of care could be shifted out of the hospitals. The best way 10 accomplish this, they believe, is by penalizing those who admit patients ro the hospital either for unnecessary treatment or for conditions which could be taken care or safely and efrectively on an outpatient basis.

The federal government is clearly committed to minimizing differences in medical care as much as possible 10 assurc inpatient admissions only for those patients who really need to be in the hospital for the management of their illness. For example, according to federal estimates, over the nex1 two years 65.000 Missourians will be treated in doctors' offices or in

\footnotetext{
From: Missouri Patient Care Review Foundation, Jefferson Cily, MO 65101

Address all correspondence to

Mohammad N. Akhter, M.D., M.P.H. Execulive

Vice President, Missoluri Patient Care Review

Foundation, 1026C Northeast Drive,

Jefferson City, MO 6510I
}

outpatient clinics for medical problems that until now would have meant admission 10 acute-care hospilals.

Medicare, the federal health insurance program for the elderly and disabled, pays nearly 40 percent of the nation's medical bills. There are new federally financed agencies call Peer Review Organizations (PROs) in cvery state whose jobs are to review the care given to Medicare parienıs. These agencies, staffed by doctors, nurses, and medical records Iechnicians exis! to assure that fedcral money is spent properly and that the patients get quality care. Eacti state PRO has recently signed a contract with the Sederal government in which ilsey agree to reduce hospiral admissions for Medicare pazients by a specific percentage over the next two years. They will do this by instiluting preadmission certification and relrospeclive review programs.

\section{Preadmission Cerlificalion Programs}

In all states PROs are required to perform preadmission certification on cerlain elective hospital admissions. We have reviewed the preadmission cerlilication programs in several statcs. The mechanism for most of these programs is the same, but specifics vary greatly. Generally, the requests for admission are received and are reviewed by a nurse. Based on the established criteria, a decision is made ejiher to approve the admission or 10 refer that particular case 10 lise physician advisor, who in turn makes a decision whelher the admission is necessary. In some stales, decisions 10 approve are made by non-physicians (RNs). However, in all states. denial decisions are 10 be made by physicians. 
Following is the procedurc for preadmission certificalion:

- Initial requests for approval are customarily made by phone to the PRO area office by the physician or the office staff. The requesis are recejucd by a review coordinator who is available at the PRO office between the hours of 9:00 a.m. and 4:00 p.m. each working day.

- Ir the patient meets the screening criteria, the admission is certified. If not, the case is referred to a physician consultant.

- The physician consultant may approve the admission based on the information provided by the coordinator, or he may contact the attending physician for further information if deemed necessary. Every effort is made by a PRO physician to contact the artending physician prior to making a denial decision.

- Generally, the decision is communicated by telephone to both the physician and the hospi1al within 24 hours of receipt of the request.

- In the case of a positive decision, written confirmation is provided to the hospital, with a copy sent to the attending physician. Wheo the decision is a denial, written confirmation is mailed to the hospital, with copies sent to the altending physician and the patient.

- The altending physician may ask for a reconsideration of a denial decision. In all such cases, the PRO provides review by another physician advisor.

- All cases which were denied but where an admison took place are subject to a full charl review for admission, quality, and DRG validation. If justification can still not be cstablished, the denial is made and the hospital is not reimbursed for that admission.

Table I shows the results of the preadmission certification program. According to the Health Care Financing Administration, the overall denial rate for preadmission certilication is 1.14 percens.

\section{Relrospective Review}

After a Mcdicare palient has been treased al a hospital and discharged and the atcending physician has attested to the principal and other diagnoses and procedures, the hospital can submit the bill to Blue Cross, which acis as the fiscal intermediary (FT) for Medicare. Uniess it is one of the relarively few conditions where prepayment review by the PRO is required, the bill is paid by the Fl once it is processed. A tape of paid Medicarc claims is prepared by the FI and forwarded to the PRO on a regular basis. It is from such tapes of paid claims that PROs draw their monthly simples of cases, by hospital, for review in the next month.
After monthly samples of the cases are selected for review, worksheets are generated for each case. (The sample may equal 100 percent of Medicare cases for that month if the hospilal has lost is favorable waiver and is under inlensified review.") The PRO office notifies cach hospital in its area of the records 10 be pulled for review and schedules an on-site visit. The only exception to scheduling an on-site visit is where the hospital has fewer than ten cases to be reviewed for that month, in which case the hospital is required to mail copies of the records to the PRO office. PRO review coordinators, generally comprised of nurses and medical records technicians, perform the reviews of those selected cases.

Using crileria approved by the PRO Board, the review coordinators review the charts for medical necessity, DRG validation, potential quality concerns, and determination of which, if any, cases should be referred to a local physician for medical review. Most PROs either develop their own criteria or use ISD-A crileria developed by InterQual which are based an severily of illness and intensily of service.

Those cases referred by a review coordinalor are forwarded for review to a physician who makes an initial determinalion based upon his/her own medical expertise and on what is in the medical record. If the reviewing physician (called a physician advisor) determines that the paticnt could have been treated as an outpatient, a leller (krown as a pending denial) is sent to the attending physician informing him/her of the review findings and providing the attending physician an opportunity to submit additional information justifying the nced for inpatient services for the case in question. The attending physician has fifteen calendar days 10 respond with additional information. If there is no additional information submitted, the pending denial becomes a final denial at the end of the fifteen days, and a letter to that effect is sent to the patient, the hospital, the attending physician, and the FI. Depending on the hospital's waiver staus, it is possible the hospital will not be paid the DRG for that patient.

If additional information is submitted by the attending physician, the case will again be reviewed by the physician advisor 10 determine if the original decision is still justified. If the pending denial decision is reversed, the attending and hospital are notified, and the case is cerlified for payment. If the physician advisor upholds the pending denial, a final denial is issued as discussed in the previous paragraph. (Figure 2)

After a denial has been made, a physician, pacient. or the hospical may ask for reconsideration of the determination. When a reconsideration is sought, the medical record, along with any additional information submitted by the atcending physician, is forwarded to another physician not involved in the initial 
decermination. Based on the decision of that physician or physicians, a final decision is made cither to overturn the denial or to uphold the initial derial. Table 2 shows the result of retrospective review. Although wide variations exist in the denial rate, the overall denial rate nationwide is 2.48 percent.

Since the PRO has very litle Mexibility in this entirc process, there are ccrlain Iroublesome spots of which physicians need to be aware:

(I) By the line you get a pending denial letter, the case may aiready be live or six months old, and you may nol remember all the details relating lo diagnosis and trea!ment.

(2) The PRO reviews only the records of the patient after discharge from the hospital and has the benefit of 100 percent hindsight.

(3) There are differences in the practice of medicine among physicians within the same area and cerlainly within different geographical areas. Some physicians admit most of their patients; others astempt to treat their patients with similar problems as outpacients.

(4) Some procedures, we all agree, can be done in an outpatient setting; but there are others that are much less clear. To what degree should we expose our patient to a risk of poor outcome for budgetary resıraints, and how much risk should a physician take in making that decision? This is a challenge.

(5) In the past three years while the increase in the gross national produch has been $12.3,4.0$, and 7.7 percent, the national health expenditures have increased at 15.1. 12.5, 12.4 percent. HCFA is serious abous reducing health care cosis, and we believe the review program is going 10 be with us for a number of years.

With these thoughts in mind, what must physicians do to avoid urnecessary denials?

(1) Understand the Systen - This is perliaps the most critical point - "What you don's know can hurt you." Physicians must understand the process, as well as the criteria, and participate in the review process as a reviewer if you have nol done so in the past.

(2) Fully Document Each Case - Poor documenlation is a major cause of referrals and denials. You have probably heard the axiom, "If it is not in the record, it didn'? happen." From a review coordiralor's or reviewing physician's perspective, that is in fact the case. To avoid an adverse decision, the reasons for admission to an acute care facility should be adequately and appropriately documenled.

(3) Know the Crileria - The criteria developed by your PRO and the ISD-A criteria published by InterQual are guidclines for review coordinators to perform screening of the chars.
Most Medicare patients admitted to hospitals meer these criteria; however, documentation is not always adequate. Charss meeting the criicria will generaily not be referred by revicw coordinators, and there will be no need for a physician advisor 10 review, and possibly deny. the case. Therefore, it is important to be inlimately familias with the criteria and to make sure that you document the appropriale clements of that criteria on the medical records.

(4) Document Reason for Admission - if your admission docs not meet PRO-established criteria, document the specific medical reasons for admission of the patient to the hospital 10 cnable review by the physician advisor in the event of a referral.

(5) Participate in the Development of the Criteria - If you have problems with the criteria or think they are inappropriate, please contact the PRO Director with your proposed changes so that he/she can refer them to the appropriale committee (I he Quality Assurance/Criteria Commitlec of the PRO) for appropriate adjusiment.

If you do get a denial, the following is recommended:

(1) Have your chart reviewed by the hospital Unilization Review Commitce to determine whether there is reason 10 believe the case should be reconsidered by the PRO. If so, let the commitice, either on your behalf or on behalf of the hospital, write a letter to the PRO for the denial reconsideration with their reasons for the request.

(2) If you have information in your office that is not a part of the origina! medical record that will justify the admission, provide that information with the record.

(3) You have sixly days from the dale of the denial leller to ask for a reconsideration. Ask promptly for reconsideration while the PRO stil has the charl at hand and the case is fresh in everybody's mind. Requests for reconsideration received after sixty days are not honored.

(4) If you feel you have been treated unfairly or that your local physicians are 100 strict in denying your cascs. you can ask for reconsideration outside your area by writing to the PRO Medical Director.

(5) Do not rake a derial lightly. The implications of a denial are far-reaching for the instirution where you practice and for you. Physicians who continuously receive denials are subject 10 100 percent review of all Medicare cases. If unnecessary admissions continue to be a problem, then preadmission certification beyond 
what is presently required of all physicians might be invoked 10 address the situation with both the physician and the hospital involved. This would mean that prior to admission of a Medicare patient, the physician would need to get approval from the PRO office. If the problem still continues unabated, then HCFA may impose sanctions such as excluding that particular practitioner from participation in Medicare.

We are very concerned about the extraordinary powers and authority granted to the Health Care Financing Adminisl ration to impose punitive actions on physicians. Some hospitals where the denial rate has gone as bigh as 20 percent have been losing money. Under current economic conditions, not being paid for services provided for Medicare patients creates an extensive burden on the hospital and puts the future of that hospital in jeopardy. During the past ten months, there has been a considerable decline in the number of Medicare cases admitted to hospitals. Denial of payment for even a smail number of cases could put a small hospital out of business.

It is important, therefore, that the physician and hospital cooperate in making sure that only those patients needing inpatient care are admitted to the hospital.

- Denial of al leasl lihree cases with $2.5 \%$ of losal cases reviewed in the previous culendur quarier leads to intensified review and lass of woivir.

FIGURE 1

PREADMISSION CERTIFICATION PROCESS

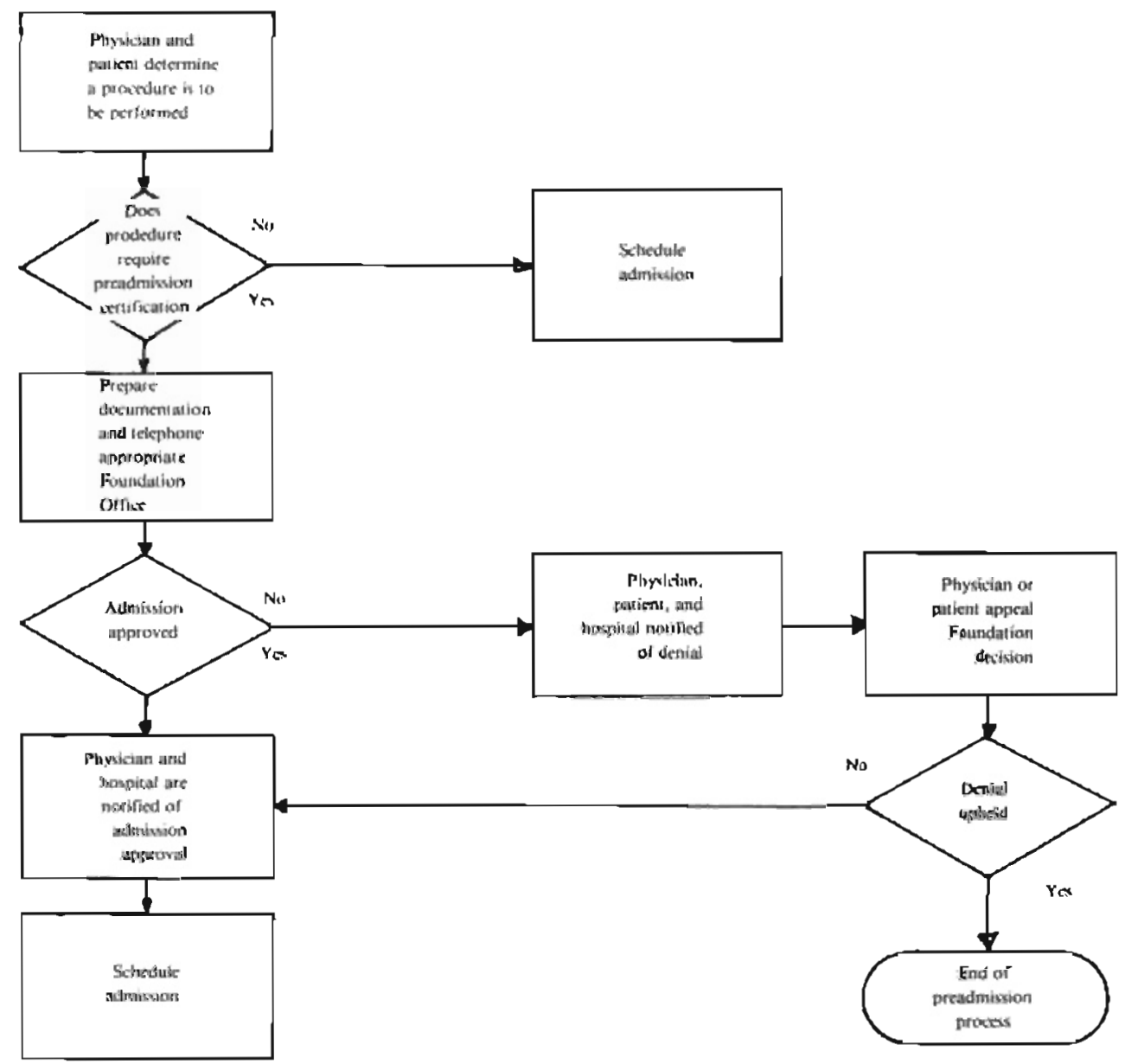


FIGURE 2

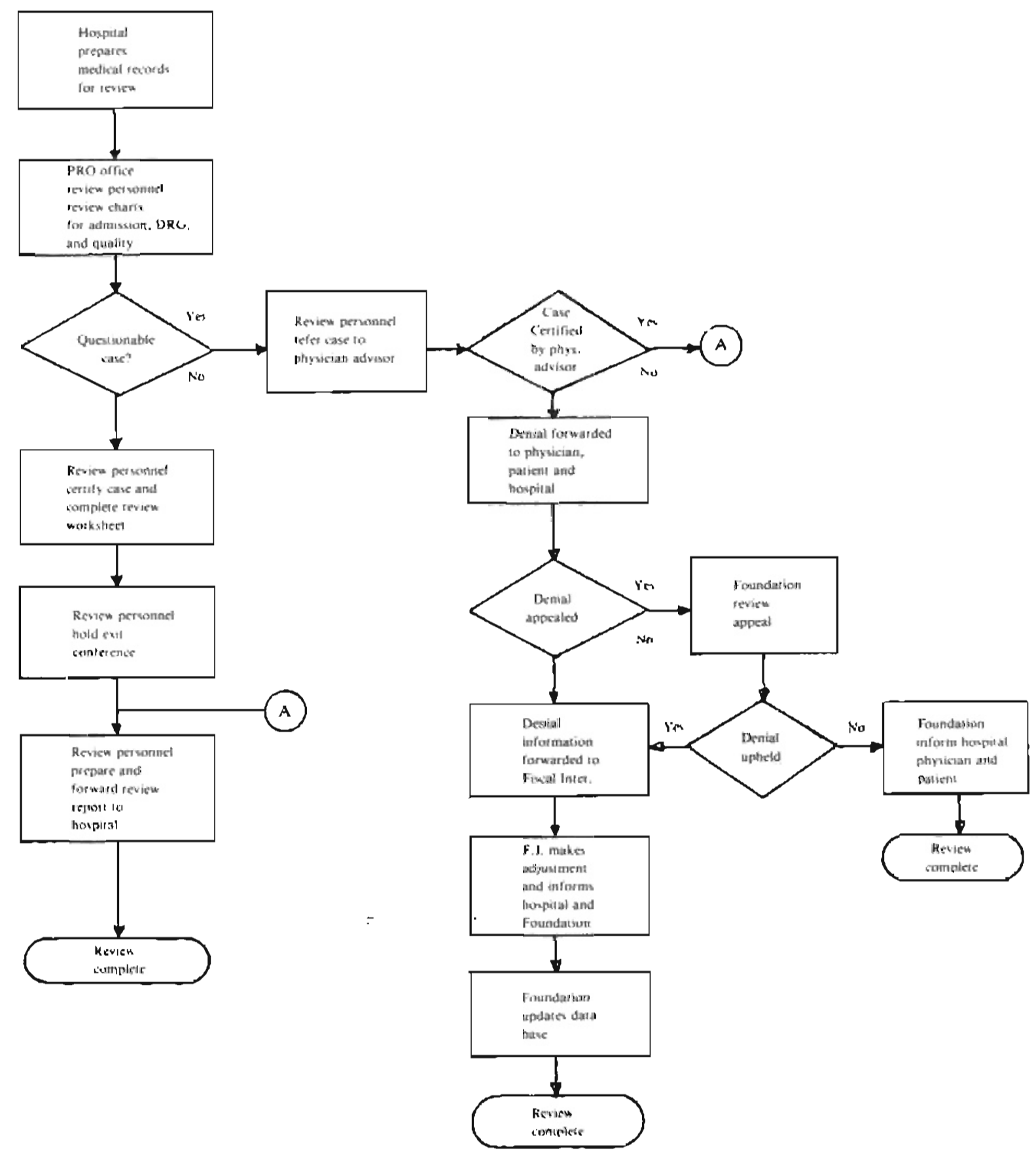


TABLE I

PREAOMISSION REVIEW SUMMARY

START-UP THROUGH APRIL 1985

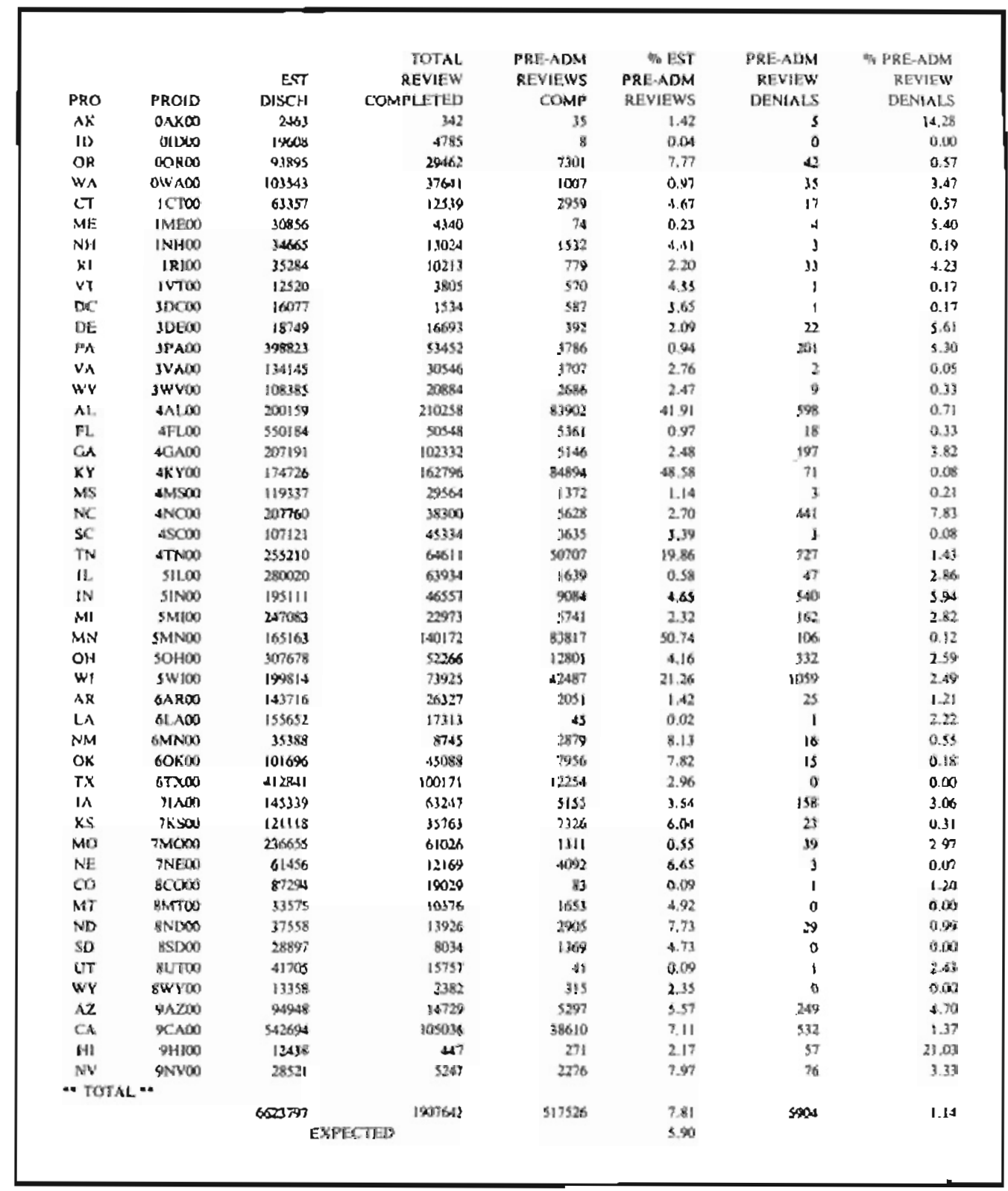

Source: Health Care Financing Administration

The Journal of IMA-Vol. 18-Jan.-June 1986-Page 13 
TABLE 2

ADMISSION REVIEW SUMMARY

START-UP THROUGH APRIL 1985

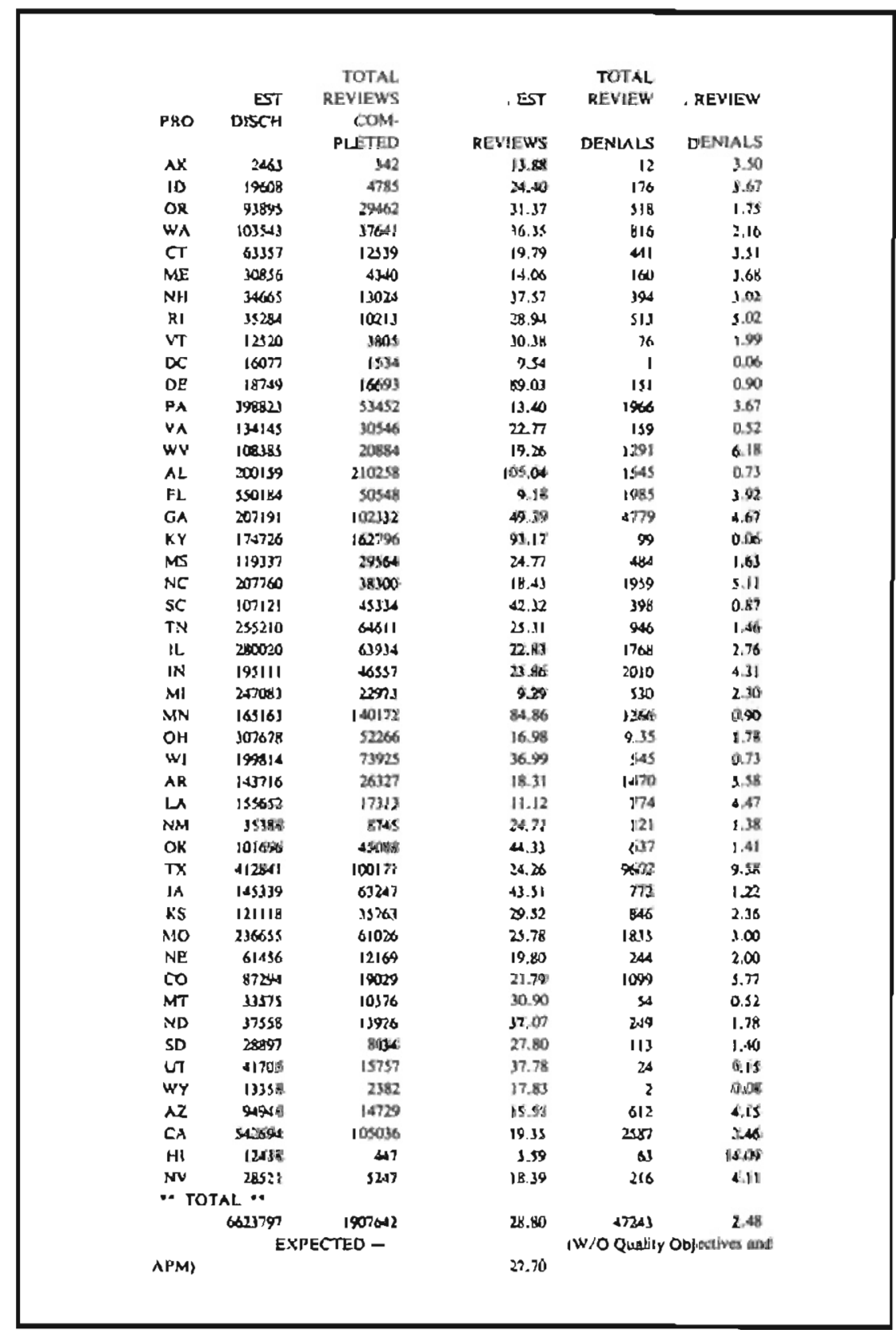

Source: Health Care Financing Administration

Page 14-The Journal of IMA-Vol. 18-Jan.-June 1986 